\title{
O câncer de esôfago: uma revisão
}

\author{
Elton Carlos de OLIVEIRA-BORGES ${ }^{1}$ \\ Adriana Fernandes SILVA ${ }^{2}$ \\ Amanda Monteiro das GRAÇAS ${ }^{3}$ \\ Fabiano Freire Santos MELO ${ }^{4}$ \\ Adler Andrade BARCELOS ${ }^{5}$ \\ Seiji MYIATA ${ }^{6}$
}

\author{
${ }^{1}$ Graduando em Medicina pela UninCor, eltonborges@ hotmail.com \\ ${ }^{2}$ Graduanda em Medicina pela UninCor, drifernandesmg@gmail.com \\ ${ }^{3}$ Graduanda em Medicina pela UninCor, amandamontegra@ hotmail.com \\ ${ }^{4}$ Graduando em Medicina pela UninCor, incisivocity@ hotmail.com \\ ${ }^{5}$ Graduando em Medicina pela UninCor, adler@dr.com \\ ${ }^{6}$ Cirurgião-Oncologista, professor da disciplina de Clínica Cirúrgica na UninCor, seijisilvana@ @erra.com.br
}

\section{Recebido em: 03/05/2015 - Aprovado em: 14/07/2015 - Disponibilizado em: 15/07/2015}

\begin{abstract}
RESUMO
O câncer de esôfago é um câncer relativamente incomum, mas de prognóstico desfavorável, associado ao alcoolismo, tabagismo e chá mate, em populações com menor nível socioeconômico. OBJETIVO: elaborar uma revisão bibliográfica sobre o câncer de esôfago, dividida nos seguintes tópicos: histórico; sintomatologia; classificação, prognóstico e estadiamento; epidemiologia, distribuição geográfica e fatores de risco; formas de diagnóstico; e tratamento. METODOLOGIA: foram revisados 23 artigos, publicados, entre os anos de 2005 a 2015, por centros de pesquisa brasileiros de São Paulo, Rio de Janeiro, Minas Gerais e Rio Grande do Sul, bem como internacionais. RESULTADO: o câncer no esôfago reúne, sob o mesmo nome, 20 diferentes histologias tumorais, marcadas pelo estabelecimento de sintomas como disfagia, odinofagia e perda de peso. Três classificações foram usadas para a sua distinção e avaliação do estadiamento, entre as quais, a Classificação Macroscópica, o Consenso de Paris, e a Classificação de Vienna p-TNM, de maior complexidade e referência. Alguns estudos sugeriram a associação de adenocarcinomas ao esôfago de Barrett e à doença do refluxo gastro-esofágico, assim como à neutralização medicamentosa do pH gástrico. Não foi relatada associação entre esôfago de Barret e carcinoma epidermóide. A sobrevivência após 5 anos é desapontadora, variando conforme o tipo histológico e o estágio do tumor. O sítio mais frequente é o terço médio. A endoscopia digestiva alta com biópsia é o exame diagnóstico mais indicado. A terapêutica mais utilizada é a neoadjuvante, com combinação entre quimio e radioterapia para redução tumoral, e melhor resultado na ressecção cirúrgica.
\end{abstract}

Palavras-chave: Câncer de Esôfago. Adenocarcinoma. Carcinoma Epidermóide. Esôfago de Barret. Disfagia.

\begin{abstract}
Esophageal cancer is a relatively uncommon cancer, but the poor prognosis, associated with alcoholism, smoking and mate tea in populations with lower socioeconomic status. OBJECTIVE: To develop a literature review on esophageal cancer, divided into the following topics: history; symptoms; classification, prognosis and staging; epidemiology, geographical distribution and risk factors; forms of diagnosis; and treatment. METHODS: we reviewed 23 articles published between the years 2005 to 2015, by Brazilian research centers of Sao Paulo, Rio de Janeiro, Minas Gerais and Rio Grande do Sul, as well as international. RESULT: cancer of the esophagus brings together, under the same name, 20 different tumor histologies, marked by the establishment of symptoms such as dysphagia, odynophagia and weight loss. Three classifications were used for their distinction and evaluation of staging, including the Macroscopic Classification, the Consensus of Paris, and Vienna Classification p-TNM, more complex and reference. Some studies have suggested the association adenocarcinomas of the Barrett's esophagus and gastro-esophageal reflux, as well as to drug neutralization of gastric $\mathrm{pH}$. It was reported association between Barrett's esophagus and squamous cell carcinoma. The survival after five years is disappointing, varying according to the histological type and tumor stage. The most frequent site is the middle third. Upper endoscopy with biopsy is the preferred diagnostic test. The most widely used therapy is neoadjuvant with combination chemotherapy and radiation therapy for tumor reduction, and better results of surgical resection.
\end{abstract}

Keywords: Esophageal cancer. Adenocarcinoma. Carcinoma Epidermóide. Barrett's esophagus. Squamous cell carcinoma. Dysphagia. 


\section{INTRODUÇÃO}

O câncer no esôfago apresenta 20 diferentes tipos histológicos, dos quais o adenocarcinoma é o mais frequente $(75 \%)$; todos, no entanto, estão associados à disfagia e à perda de peso. A porcentagem de pacientes que sobrevivem após cinco anos é desapontadora, mas varia conforme a classificação do tumor: $10 \%$ no carcinoma epidermóide tipo basalóide e $25 \%$ no sarcoma sinovial, pode chegar, entretanto, a $95 \%$ no carcinoma de células escamosas em estágio inicial.

Este artigo tem como objetivo reunir uma síntese sobre tamanho mal, a partir de artigos publicados entre os anos de 2005 a 2015, contemplando os seguintes tópicos: (1) Histórico, (2) Sintomatologia, Classificação, Prognóstico e Estadiamento, (4) Epidemiologia, Distribuição Geográfica e Fatores de Risco, (5) Formas de Diagnóstico, e (6) Tratamento. Foram analisadas publicações nos idiomas português e espanhol, produzidas por universidades e centros de pesquisa brasileiros, sediados nos Estados de São Paulo, Rio de Janeiro, Minas Gerais e Rio Grande do Sul, além de centros de pesquisa de referência localizados em outras partes do mundo.

\section{Histórico}

$\mathrm{Na}$ literatura analisada, não foram encontradas referências históricas sobre o câncer no esôfago, com exceção da citação de Garbino (2005) sobre o primeiro caso de carcinoma de esôfago tipo células pequenas, publicado por Kelsen e colaboradores, em 1980.

\section{Sintomatologia}

Em relação aos sintomas, os exemplos mais detalhados foram dados pelos trabalhos de Ximenes Netto et al. (2011) e (2012), Alencar et al. (2012), e Cambruzzi et al. (2013), sobre a manifestação de odinofagia (dor durante a deglutição), disfagia (dificuldade para deglutição), perda de peso, dor torácica, febre, fadiga, desidratação e alteração no timbre da voz; a disfagia foi progressiva com necessária ingestão de líquidos durante a deglutição; os vômitos pósprandiais de alimentos pouco digeridos ocorreram após 30’ em média, e o emagrecimento chegou a $10 \mathrm{~kg}$ em 4 meses No carcinoma epidermóide tipo basalóide, os sintomas mais comuns foram a disfagia e a perda de peso, havendo, em mais da metade dos casos, envolvimento linfonodal já no diagnóstico. $\mathrm{O}$ mesmo pode crescer e atingir grandes proporções sem qualquer sintoma ou cursar com lesão cáustica, acalasia, doença diverticular ou do refluxo, além de tosse e hematêmese. (XIMENES NETTO et al. 
(2011) e (2012); CAMBRUZZI et al., 2013; ALENCAR et al, 2012).

\section{Classificações histológicas, Estadiamento e Prognóstico}

Quanto às referências sobre classificações histológicas, estadiamento e prognóstico, as melhores foram encontradas em Queiroga e Pernambuco (2006), Seineldin e Seineldin (2007), Garrido (2011), Veas e Flisfisch (2011), Ximenes Netto et al. (2011), Arantes (2012), Lacerda (2013) e Cambruzzi et al. (2013).

Segundo a Organização Mundial da Saúde, os tumores malignos que acometem o esôfago subdividem-se em 20 tipos, quais sejam, (1) carcinoma epidermóide tipo usual; (2) carcinoma epidermóide com variantes; (3) carcinoma basalóide; (4) carcinosarcoma; (5) carcinoma verrucoso; (6) carcinoma tipo linfoepitelial; (7) adenocarcinoma associado a esôfago de Barrett; (8) carcinoma adenóide cístico; (9) carcinoma misto epidermóide/glandular e tumores compostos; (10) carcinoma adenoescamoso; carcinoma mucoepidermóide; (12) carcinoma de célula pequena; (13) coriocarcinoma; (14) tumores não epiteliais; (15) leiomiosarcoma; (16) rabdomiosarcoma; (17) sarcoma de Kaposi; (18) melanoma maligno; (19) tumores secundários; e (20) carcinoma epidermóide invasivo com achados macro e microscópicos. (OMS citado por XIMENES NETTO et al., 2011).

Queiroga e Pernambuco (2006), Veas e Flisfisch (2011) afirmam que o sítio mais frequente do câncer no esôfago é o terço médio, sendo os terços superior e inferior, entre si, de percentual semelhante, mas com tendência de aumento no terço inferior em função da crescente incidência de refluxo gastresofágico crônico e Esôfago de Barret (EB). Seineldin e Seineldin (2007), por outro lado, defendem valores diferenciados de frequência de localização, sendo $50 \%$ no terço médio; $30 \%$ a $35 \%$ no terço inferior e, apenas, $1 \%$ no terço superior. Para Cambruzzi et al. (2013), o sítio mais comum é o terço inferior do esôfago, podendo o carcinoma de células escamosas ocorrer em qualquer parte, mas, especialmente, no terço médio e o inferior.

Cambruzzi et al. (2013) ressaltou que o esôfago é um dos locais mais comuns de tumores de células granulares (tumor de Abrikossoff) no trato gastrointestinal, sendo solitários, incidentais, de pequena lesão e crescimento lento. Tumores múltiplos são encontrados em cerca de $10 \%$ dos casos, e podem levar à obstrução.

Queiroga e Pernambuco (2006) classificaram histologicamente tais tumores em (1) carcinoma epidermóide ou escamoso e (2) adenocarcinoma; o primeiro derivado do epitélio estratificado não queratinizado, característico da mucosa normal do esôfago, 
tem como variantes o (1.1) carcinoma verrucoso, o (1.2) carcinoma epidermóide tipo basilóide e o (1.3) carcinoma epidermóide sarcomatóide. Já o (2) adenocarcinoma no interior do epitélio colunar displásico, principalmente, na junção esôfagogástrica/cárdia, com refluxo gástrico crônico e metaplasia gástrica do epitélio, além de aneuploidias e mutações do p53, mesmo antes da neoplasia se tornar detectável. Suas variantes raras incluem o (2.1) carcinoma mucoepidermóide e o (2.2) carcinoma adenóide-cístico.

De acordo com o Consenso de Paris citado por Arantes (2012), as lesões superficiais no esôfago apresentam 3 subtipos: (1) protuso (tipo 0-I), (2) plano (tipo 0-II) e (3) escavado (tipo 0-III). As lesões protusas são subclassificadas em (1.1) pediculada (0-Ip), (1.2) subpediculada (0-Isp) e (1.3) séssil (0-Is). No esôfago são mais frequentes as neoplasias superficiais planas, subdivididas em (2.1) superficialmente elevadas em relação à mucosa adjacente (IIA), (2.2) planas (IIB) e (2.3) deprimidas (IIC), sendo raras as formas (1) protusa e (3) escavada. Tais neoplasias podem, ainda, ser subdivididas segundo o grau de penetração transmural: M1 corresponde ao epitélio e camada basal; M2 à lâmina própria ou córion; e M3 à muscular da mucosa. O comprometimento da submucosa também pode ser subdividido em SM1 (terço superior), SM2 (terço médio) e SM3 (terço inferior). (ARANTES, 2012).

Em relação à denominação histopatológica das neoplasias superficiais, a recomendação atual é que seja adotada a normatização de terminologia proposta pela Classificação de Vienna / p-TNM ("p" de patologia). Na ausência de invasão da lâmina própria, a lesão é denominada neoplasia intraepitelial de baixo ou alto grau, além de in situ (pTis). Ocorrendo a invasão da lâmina própria a neoplasia esofagiana é denominada carcinoma intramucoso ou microinvasivo (pT1m). Em caso de infiltração da camada submucosa, a neoplasia é considerada invasora $(\mathrm{pT} 1 \mathrm{sm})$. Deve-se destacar que o risco de metástase linfonodal em neoplasias superficiais é determinado pela profundidade de invasão da lesão na parede do órgão, critério este que define a necessidade do tratamento endoscópico com fins curativos: (1) se o acometimento é limitado ao epitélio (M1) e à lâmina própria do esôfago (M2), o risco de disseminação linfonodal é próximo a zero, sendo a excisão local completa suficiente para a cura; (2) se a lesão invade a musculares mucosa (M3) e a porção superior da submucosa até a profundidade de 200ì (SM1), o risco é de 9\% a 19\%; (3) se o tumor atinge focalmente as camadas M3/SM1, com tamanho da lesão menor que $3 \mathrm{~cm}$, inexiste invasão linfovascular e o acometimento da lâmina musculares mucosa tem largura inferior a 3mm, o risco de metástase 
linfonodal é muito baixo (1,5\%); (4) em caso de infiltração acentuada da submucosa (SM2 e SM3), metástases linfonodais ocorrem em $40 \%$ dos casos. (ARANTES et al., 2012).

Cambruzzi et al. (2013), por sua vez, focalizaram uma classificação na qual os tumores primários do esôfago, com nódulo mal circunscrito, firme e amarelo-pálido, na submucosa, são definidos segundo sua origem celular em epiteliais e não epiteliais, benignos e malignos. Afirmaram, ainda, que quase todos os cânceres de esôfago são carcinomas, sendo raros os sarcomas; já os tumores não epiteliais são de maioria benigna, sobre tecido de estroma mesenquimal; os tumores compostos são, por sua vez, tumores originados de forma separada, em locais adjacentes, que se fundem, à medida que crescem, invadindo um ao outro.

Em relação à extensão e classificação macroscópica, Seineldin e Seineldin (2007) afirmaram que os cânceres de esôfago apresentam, no diagnóstico, tamanho entre 4 e $5 \mathrm{~cm}$, assim como três possíveis tipos macroscópicos de lesões:

(1) vegetantes: os mamelões neoplásicos (montículos) proliferam-se para o interior da luz, alcançando considerável tamanho, sobre ampla base e de bordas definidas; a apresentação pedicular é improvável, apesar de serem comuns pequenas excrescências polipóides nas margens; na superfície, nos focos de necrose são originadas crateras de diferentes extensões e profundidade;

(2) ulcerados: os mamelões neoplásicos apresentam menor extensão que os vegetantes, e forma de úlcera com bordas grossas, evertidas e irregulares, sobre fundo da cratera hemorrágico e escarpado; toda a espessura de sua parede pode ser atravessada por crescimento tumoral e o diâmetro maior é orientado para o eixo longitudinal do esôfago;

(3) infiltrantes: os mamelões caracterizam-se por abundante estroma fibroso, infiltrado em toda espessura da parede ou como ilhotas descontínuas, circunferenciais, pouco estendidas, com calibre exterior pouco alterado, de menor elasticidade, e com finas verrucosidades; a estenose é consequência do engrossamento parietal e da retração do tecido tumoral. Embora possuam aspecto fibroso, esses tumores costumam ser de desfavorável evolução.

Seineldin e Seineldin (2007), ressaltaram que em função da origem embrionária esofágica ser ectodérmica com 
produção de epitélio pavimentoso estratificado, a variedade cancerígena mais frequente é a epidermóide (escamosa), incidente entre $93,7 \%$ e $78,5 \%$ dos casos, por implantação nas paredes esofágicas ou infiltração cefálica de tumor gástrico. Queiroga e Pernambuco (2006), Veas e Flisfisch (2011) confirmaram o carcinoma epidermóide escamoso como o tipo mais frequente $(75 \%)$, exofítico, ulcerado, infiltrante, de precoce invasão local e metástase à distância; sendo o segundo tipo o adenocarcinoma, no terço médio inferior, mais associado ao Esôfago de Barret (EB), com rápida disseminação linfonodal e acentuada incidência em obesos; carcinomas adenoescamosos, melanomas ou sarcomas são infrequentes, representando menos de $1 \%$ dos casos. Já Ximenes Netto et al., em revisão de 2011, assumiram como tipo mais frequente (75\%) o adenocarcinoma, ao invés do carcinoma escamoso. Garrido (2011) esclareceu que o carcinoma de células escamosas ocorre mais no nível do terço superior e médio, enquanto que, no terço inferior, há predomínio de adenocarcinoma. Para aumentar o dissenso, Cambruzzi et al. (2013), atribuíram ao carcinoma espinocelular o tipo mais comum dos tumores malignos do esôfago, nos homens, aos 60 anos de idade.

Ximenes Netto et al. (2011), por sua vez, assumiram o linfoma primário do esôfago, como o tipo mais raro, apresentando menos de 30 casos relatados na literatura mundial. Sem uma etiologia identificada, as infecções pelos vírus HIV e Epstein-Barr foram relatadas como os seus fatores de risco (XIMENES, 2008), e afirmadas como item no diagnóstico diferencial de HIV-AIDS, uma vez que pacientes HIV+ apresentam 104 vezes mais risco de linfoma de esôfago.

Tido por grande parte dos autores como o tipo mais frequente, o carcinoma epidermóide, segundo Seineldin e Seineldin (2007), é bem diferenciado, com queratinização central e certa organização celular, podendo ser moderadamente diferenciado; os pobremente diferenciados apresentam polimorfismo celular, hipercromatismo nuclear e elevado número de mitoses, não sendo possível definir seu caráter epidermóide. No tipo pseudosarcomatoso ou fusiforme, variante do epidermóide, são observadas células com aspecto de fuso semelhante aos sarcomas de outros sítios.

De acordo com Seineldin e Seineldin (2007), o adenocarcinoma tem, por seu tempo, origem associada a áreas de metaplasia intestinal ou ilhotas ectópicas de mucosa gástrica, com variantes mucoepidermóide e adenocística. Já os carcinomas precoces são raramente reconhecidos nos primeiros estágios, sendo as lesões iniciais pequenas, com erosão inespecífica, placa queratótica e imagem polipóide; o tipo papilar é menos frequente, mas comprometer a camada muscular.

Garbino et al. (2005) caracterizaram o 
carcinoma de esôfago por pequenas células, redondas, ovais, poligonais, com núcleo hipercromático e escasso citoplasma, dispostas em colunas e lâminas ou rosetas, com grânulos neurosecretantes citoplasmáticos. No esôfago são menos frequentes o carcinoma verrucoso, o carcinoma epidermóide basalóide e as neoplasias não epiteliais como o tumor estromal gastrointestinal (GIST) e o melanoma maligno. (LACERDA, 2013).

De outro modo, os tumores de caráter benigno são raros e, grande parte das vezes, assintomáticos, com incidência maior entre os 30 e 59 anos de idade, sendo o tumor mais frequente o leiomioma, e o menos, o fibroma, o lipoma, o hemangioma, o neurofibroma e o tumor mesenquimatoso benigno. (GARRIDO, 2011; CAMBRUZZI et al, 2013).

O fator prognóstico mais importante é o estadiamento baseado no sistema TNM, destacado na Tabela I a seguir. Nos pacientes em que o tumor não vai além da submucosa, a sobrevida pode chegar a $70 \%$, comparado à sobrevivência de, apenas, $30 \%$ a $50 \%$ dos pacientes nos quais há invasão da musculares própria e adventícia. (XIMENES NETTO et al., 2011).

Tabela I: Sistema TNM na classificação dos tumores malignos do esôfago

\begin{tabular}{|c|c|c|c|}
\hline Tumor primário (T) & $\begin{array}{c}\text { Linfonodos regionais } \\
(\mathbf{N}) \\
\end{array}$ & Metástases distantes & $\begin{array}{c}\text { Estadiamento por } \\
\text { Grupos } \\
\end{array}$ \\
\hline $\begin{array}{l}\text { TX tumor primário não } \\
\text { pode ser acessado }\end{array}$ & $\begin{array}{l}\text { NX linfonodos regionais } \\
\text { não podem ser acessados }\end{array}$ & $\begin{array}{l}\text { MX metástases não } \\
\text { podem ser acessadas }\end{array}$ & Estágio 0 Tis N0 M0 \\
\hline $\begin{array}{l}\text { T0 Sem evidência do } \\
\text { tumor primário }\end{array}$ & $\begin{array}{l}\text { No linfonodos regionais } \\
\text { não envolvidos }\end{array}$ & $\begin{array}{l}\text { M0 sem metástases } \\
\text { distantes }\end{array}$ & Estágio I T1 N0 M0 \\
\hline $\begin{array}{l}\text { Tis Carcinoma in } \\
\text { situ/displasia de alto grau }\end{array}$ & $\begin{array}{l}\text { N1 linfonodos regionais } \\
\text { envolvidos }\end{array}$ & M1 metástases distantes & $\begin{array}{lll}\text { Estágio } & \text { IIA } & \text { T2-T3 } \\
\text { N0 MO } & & \end{array}$ \\
\hline $\begin{array}{l}\text { T1 Tumor que invade a } \\
\text { lâmina própria ou } \\
\text { submucosa }\end{array}$ & $\begin{array}{l}\text { N1a - 1-3 linfonodos } \\
\text { envolvidos }\end{array}$ & $\begin{array}{l}\text { Para os tumores do } \\
\text { esôfago torácico inferior }\end{array}$ & $\begin{array}{lll}\text { Estágio } & \text { IIB } & \text { T1-T2 } \\
\text { N1 M0 } & & \end{array}$ \\
\hline $\begin{array}{l}\text { T1a Tumor invade a } \\
\text { lâmina própria }\end{array}$ & $\begin{array}{l}\text { N1b } \quad-4-7 \text { linfonodos } \\
\text { envolvidos }\end{array}$ & $\begin{array}{l}\text { M1 a - metástases no } \\
\text { tronco celíaco }\end{array}$ & $\begin{array}{l}\text { Estágio } \text { III } \mathrm{T} 3 \text { N1 } \\
\text { M0 }\end{array}$ \\
\hline $\begin{array}{l}\text { T1b Tumor invade a } \\
\text { submucosa }\end{array}$ & $\begin{array}{l}\text { N1c - > } 7 \text { linfonodos } \\
\text { envolvidos }\end{array}$ & $\begin{array}{l}\text { M1 b - outros locais de } \\
\text { metástases }\end{array}$ & T4 Qualquer N M0 \\
\hline $\begin{array}{l}\text { T2 Tumor invade } \\
\text { musculares própria }\end{array}$ & & $\begin{array}{l}\text { Para os tumores do } \\
\text { esôfago torácico superior }\end{array}$ & $\begin{array}{l}\text { Estágio IV Qualquer } \\
\text { T Qualquer M M1 }\end{array}$ \\
\hline $\begin{array}{l}\text { T3 Tumor invade a } \\
\text { adventícia }\end{array}$ & & $\begin{array}{l}\text { M1a - Metástases nos } \\
\text { linfonodos cervicais }\end{array}$ & 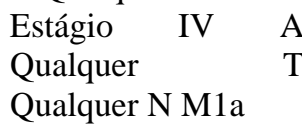 \\
\hline $\begin{array}{l}\text { T4 Tumor invade } \\
\text { estruturas adjacentes }\end{array}$ & & $\begin{array}{l}\text { M1b - Outras metástases } \\
\text { distantes }\end{array}$ & $\begin{array}{l}\text { Estágio IV } \\
\text { Qualquer } \\
\text { Qualquer N M1b }\end{array}$ \\
\hline & & $\begin{array}{l}\text { Para os tumores do } \\
\text { esôfago médio } \\
\text { M1a - não se aplica } \\
\text { M1b - Sem linfonodos } \\
\text { regionais ou metástases } \\
\text { distantes }\end{array}$ & \\
\hline
\end{tabular}

Fonte: American Joint Committee on Cancer (2002) citado por Ximenes Netto et al. (2011). 
A sobrevivência de um paciente após 5 anos, em caso de carcinoma epidermóide tipo basalóide é de $10 \%$ a $15 \%$ (XIMENES NETTO et al., 2011); de sarcoma sinovial, de $25 \%$ a $65 \%$ (ARANTES et al., 2012) ou incerta (ALENCAR et al., 2012); de carcinoma epidermóide escamoso, de $30 \%$ a 40\% (XIMENES NETTO et al., 2011), e, no carcinoma de células escamosas, em estágio inicial, de até $95 \%$.

Entretanto, apesar do progresso nos últimos anos com o tratamento cirúrgico e ressecção completa, Tercioti Junior et al. (2011) afirmaram que a sobrevida a longo prazo é bastante desapontadora. Para Arantes et al. (2012), o prognóstico é reservado, com taxa de sobrevida em 5 anos de apenas $15 \%$ e taxa de recidiva local de até $70 \%$ das vezes, com metástases para o pulmão, linfonodos e medula óssea. Cambruzzi et al. (2013) destacaram uma sobrevida uniformemente baixa, com taxa em 5 anos inferior a $10 \%$.

\section{Epidemiologia, Distribuição Geográfica e}

\section{Fatores de Risco}

O câncer de esôfago é uma neoplasia maligna relativamente incomum e extremamente letal. Acomete mais homens do que mulheres, depois dos 50 anos de idade, sendo maior a incidência aos 65 anos, e níveis socioeconômicos mais baixos. Na América do Norte e na Europa Ocidental, a doença é muito mais comum em negros do que em brancos. Uma característica interessante é a sua rara ocorrência antes dos 30 anos. (QUEIROGA e PERNAMBUCO, 2006; WÜNSCH FILHO et al., 2010; MELO et al., 2012).

O câncer de esôfago é o oitavo tipo de câncer mais incidente na população no mundo. (TERCIOTI JUNIOR et al., 2011). A epidemiologia do câncer de esôfago, especialmente do adenocarcinoma, responsável por $75 \%$ de todos os casos esofágicos, apresenta maior incidência no Ocidente, especialmente nos países mais desenvolvidos, com fatores de risco relacionados a estilo de vida, assim como práticas culturais e médicas, incluindo maior aporte de novos métodos de diagnóstico e tratamento. O segundo tipo mais frequente, o carcinoma epidermóide, está mais associado a pessoas de baixa classe social, e passado de álcool e fumo, na parte sul do mar Cáspio, Turquia, Rússia e nordeste da China; na Índia, Sri Lanka, Sudeste da África, e nordeste da França varia entre 10 e 50 por 100,000 pessoas; no Brasil a maior prevalência se encontra no Rio Grande do Sul, em função do uso de chá quente. (XIMENES NETTO et al., 2011).

O tabagismo e o alcoolismo atuam de forma sinérgica, especialmente no tipo epidermóide, aumentando o risco em 5-10 vezes comparado a não fumantes. As 
inúmeras substâncias químicas existentes no tabaco levam a mutações no gene p53 que induzem a carcinogênese mais cedo no tipo epidermóide do que no tipo adenocarcinomóide. O alcoolismo associado ao tabagismo aumenta em 100 vezes o risco do tipo epidermóide, o mesmo não sendo verdade para o adenocarcinoma, no qual parece reduzir com o uso moderado do vinho. (XIMENES NETTO et al., 2011).

Entre as doenças associadas, as mais citadas são a (1) tilose (síndrome de HowelEvans, hiperceratose da palma das mãos e planta dos pés) com $100 \%$ de risco; (2) acalasia e síndrome de Plummer-VinsonPatterson-Kelly (disfagia pós-cricóide e deficiência de ferro), todas associadas à lesão inflamatória crônica; (3) ingestão de soda cáustica, (4) bandas esofagianas e estenoses induzidas por irradiação, (5) câncer de cabeça e pescoço, e, (6) infecção por HPV Papiloma Vírus Humano. (QUEIROGA e PERNAMBUCO, 2006; XIMENES NETTO et al., 2011). Além dos fatores anteriores, Cambruzzi et al. (2013), também destacaram como possíveis fatores etiológicos a deficiência alimentar, a contaminação fúngica dos alimentos, acalasia, divertículo esofágico, e doença celíaca, além de esofagite crônica (CAMBRUZZI et al., 2013). Dentre todos estes fatores, a história de carcinoma de células escamosas de vias aerodigestivas superiores (VADS) é o que guarda relação mais consistente com neoplasia sincrônica ou metacrônica de esôfago. (ARANTES et al., 2012).

O câncer de esôfago constitui a terceira causa de morte por câncer no sistema digestivo. No Brasil, em 2012, surgiram quase 10.500 novos casos de câncer de esôfago, 7770 em homens e 2650 em mulheres. O carcinoma de células escamosas (CCE) de esôfago predomina nos homens $(3,6: 1)$, entre os 50 e 70 anos de vida; com taxa de mortalidade, no sul do Brasil, de 14,3 homens e de 4,2 mulheres para cada 100.000 habitante.

O carcinoma epidermóide tipo basalóide é altamente agressivo, com prognóstico igual ou pior ao da variante epidermóide. O carcinoma epidermóide tipo verrucoso é extremamente raro e afeta principalmente os homens em idade adulta (36 a 75 anos). O carcinosarcoma representa $2 \%$ dos tumores malignos do esôfago, e acomete predominantemente homens adultos jovens. (XIMENES NETTO et al., 2011).

Ximenes Netto et al. (2011) assinalaram que mais de $95 \%$ dos tumores tipo adenocarcinoma estão associados ao esôfago de Barrett e à doença do refluxo gastro-esofágico. O chamado esôfago de Barrett (EB) é tido como precursor em até $70 \%$ dos casos ressecados de câncer da junção esofagogástrica e esôfago, incidência descrita em $1 \%$ da população assintomática, e em 10\% daquela com refluxo gastresofagiano, predominantemente em homens adultos 
jovens, brancos e obesos (IMC $>30 \mathrm{Kg} / \mathrm{m}^{2}$ ). Não foi relatada associação entre EB e câncer epidermóide. Alguns estudos demonstraram que o efeito da DRGE na gênese do adenocarcinoma é independente de outras variáveis, tais como, idade, índice de massa corporal e tabagismo. Antagonistas de receptores $\mathrm{H} 2$ e inibidores da bomba de prótons tem de forma significativa alterado o tratamento da úlcera péptica e da DRGE, abordagem que altera e promove a proliferação bacteriana com a neutralização do $\mathrm{pH}$ gástrico, o que pode estar por trás do aumento da incidência de adenocarcinoma.

O uso de ácido acetil salicílico (AAS) e drogas anti-inflamatórias não-esteroidais (DAINE) pode exercer um efeito protetor contra o desenvolvimento do adenocarcinoma do esôfago pela inibição de ciclo-oxigenases e prostaglandinas com a consequente alteração dos fatores de crescimento tumoral e aumento imunitário. (XIMENES NETTO et al., 2011).

Uma provável associação entre a colecistectomia e risco elevado de adenocarcinoma do esôfago, possivelmente por uma toxicidade do refluxo duodenal na mucosa esofagiana também foi destacada. (QUEIROGA e PERNAMBUCO, 2006).

\section{Formas de Diagnóstico}

Muitas são as formas de diagnóstico do câncer no esôfago, encontrando-se, entre as quais, o exame endoscópico com biópsia e citologia esfoliativa, a tomografia computadorizada do tórax, o PET-Scan com 18-fluorodeoxiglicose (Positron Emission Tomography), a ultrassonografia endoscópica (USE), a toracoscopia e a laparoscopia. No entanto, de acordo com Ximenes Netto et al. (2011), a melhor estratégia para o diagnóstico e subsequente tratamento do câncer de esôfago ainda não foi determinada porque a utilização de todas as técnicas disponíveis não é possível tendo em vista a escassez de recursos, tanto do ponto de vista financeiro como humano.

O exame indicado inicialmente é a endoscopia digestiva alta com biópsia, considerada sua capacidade de avaliar a localização, extensão e natureza pedunculada do tumor, elementos essenciais para a definição etiologia e o planejamento cirúrgico. (XIMENES NETTO et al., 2011). Um esofagograma com contraste, por sua vez, possibilita a obtenção de imagens de estenose ou ulcerações no esôfago, enquanto uma fibroendoscopia alta pode revelar massa friáveis ou ulceradas. (AYALA et al. 2007, PLAZAS, 2015).

A tomografia computadorizada (TC) de tórax, abdômen e pelve com contraste intravenoso (flúor-desoxiglicose F18) é a melhor tecnologia para avaliação de metástases distantes, especialmente, em linfonodos celíacos, fígado, pulmões e ossos, além de estruturas vizinhas, tais como aorta, traqueia e coluna torácica. (AYALA et al. 
2007, XIMENES NETTO et al., 2011; PLAZAS, 2015).

A ultrassonografia endoscópica (USE) pode predizer o estágio do tumor em $80-90 \%$ dos pacientes, além da extensão metastática até os nódulos linfáticos em 70-80 \% dos pacientes. A habilidade para detectar a invasão do nódulo linfóide regional tem aumentado com a realização da punçãoaspiração com agulha fina (PAAF) guiada por ultrassonografia endoscópica. É o método mais utilizado para a determinação do estágio correto (prognóstico) e para identificar, de forma adequada, lesões superficiais, as quais requerem somente tratamento cirúrgico. (AYALA et al. 2007, PLAZAS, 2015).

A melhor alternativa, no momento, é o uso combinado da TC-USE, seguido de biópsia por agulha fina, se a TC for negativa para metástases distantes. (XIMENES NETTO et al., 2011).

\section{Tratamento}

Em relação à terapêutica contra o câncer no esôfago, a conduta mais utilizada tem sido a neoadjuvante combinando quimio e radioterapia, seguida por cirurgia. Neste tópico, a maior parte das referências foi afirmada por Mata, Llach e Bordas (2007), Merino (2010), Tercioti Junior (2011) e Ximenes Netto et al., (2011), sendo o restante afirmado por Queiroga e Pernambuco (2006),
Ayala et al. (2007), Solari (2010), Arantes (2012), Henriques et al. (2012), Tortosa (2012), Lacerda (2013), Petropoulos et al. (2015), e Plazas (2015), além de Rubenstein e Shaheen (2015).

A maioria dos casos de câncer de esôfago apresenta-se avançado localmente, estando a metade dos doentes com micrometástases distantes, não sendo, portanto, passível de cura. Outros pacientes são inoperáveis, não podendo ser levados à cirurgia. De outro modo, nos pacientes com indicação cirúrgica, os tumores e linfonodos são ressecáveis e a reconstrução do trânsito esofágico, possível. (QUEIROGA e PERNAMBUCO, 2006).

Uma possibilidade de tratamento é a monoterapia, mas a maioria exige conduta multidisciplinar. (PLAZAS, 2015). Os resultados obtidos com o uso único da radioterapia contra o câncer de esôfago têm sido ruins. A sobrevida global em cinco anos de pacientes tratados pela radioterapia apenas tem variado entre $0 \%$ e $10 \%$, mas estes estudos incluem pacientes com estado geral comprometido, o que, provavelmente, inclui pessoas com doença sistêmica. Os melhores resultados foram obtidos nos portadores de tumores do tipo histológico epidermóide $(\leq 5$ $\mathrm{cm}$ ) que podem atingir 5 anos de sobrevida, em até $17 \%$ dos casos. Porém, a maioria dos relatos incluem sobrevida menor do que $10 \%$ com tal modalidade de tratamento. A radioterapia exclusiva deve ser reservada aos 
pacientes intolerantes a outras formas de terapia. (XIMENES NETTO et al., 2011).

$\mathrm{Da}$ mesma forma, a quimioterapia como forma exclusiva de tratamento do câncer de esôfago tem apresentado resultado limitado, embora boa resposta radiográfica seja verificada em até metade dos pacientes, após dois ou três ciclos de quimioterapia, inclusive com melhora da disfagia. Os novos medicamentos incluem a cisplatina, o 5fluorouracil, e, ainda mais recentemente, paclitaxel, taxotere e bleomicina. (XIMENES NETTO et al., 2011).

Diante de sintomas de obstrução, são elevadas as possiblidades de que o câncer tenha invadido a camada muscular e haja metastatizado regionalmente, ou à distância. (MERINO, 2010). Assim, o tratamento deve melhorar não só o controle local, mas, também, distante do tumor por meio de tratamento neoadjuvante entre quimio / radioterapia ou combinado, antes da abordagem cirúrgica. As vantagens da neoadjuvância são a (1) melhora da ressectabilidade pela diminuição do tumor; (2) aumento da eficiência quimioterápica, antes do rompimento do suprimento sanguíneo tumoral / linfonodal; (3) melhora do tratamento sistêmico antes da cirurgia; (4) aumento da sensibilização das células tumorais pós-quimioterápicos. (XIMENES NETTO et al., 2011). A terapia neoadjuvante deve ser finalizada entre três a quatro semanas antes da cirurgia. (TERCIOTI JUNIOR, 2011).

Terciotti Junior (2011), Rubenstein e Shaheen (2015), Petropoulos et al. (2015) defendem o tratamento neoadjuvante contra o câncer metastatizado, mas afirmam que, apesar dos recentes avanços, o aumento global das taxas de sobrevivência não foi considerável, ficando entre 5 a 15\%, apenas.

Em relação às desvantagens da terapia neoadjuvante, devem ser destacados o retardo do procedimento cirúrgico; edema e fibrose mediastinais dificultadores da operação; acúmulo de secreções pulmonares no préoperatório com deterioração da ventilação pulmonar; anemia e leucopenia. O surgimento de fístula esôfago-brônquica é de baixa frequência. (TERCIOTI JUNIOR, 2009).

A cirurgia tem sido o mais sólido pilar no tratamento. A esofagectomia requer laparotomia, associada ou não à toracotomia. Realiza-se também linfadenectomia regional. (AYALA et al., 2007; TORTOSA, 2012). Devido ao estreitamento infranqueável do esôfago, pode ser necessária a realização de gastrostomia por via endoscópica ou cirúrgica. (PLAZAS, 2015). A ressecção mais utilizada é a via transtorácica direita ou transhiatal. Não existem estudos retrospectivos nem prospectivos, que tendam para um dos dois procedimentos quanto à sobrevida, mortalidade e morbidade. (SOLARI, 2010).

O tratamento endoscópico de 
neoplasia superficial está indicado em caso de comprometimento em profundidade restrito às camadas M1 e M2 (epitélio e lâmina própria); extensão longitudinal máxima de $3 \mathrm{~cm}$, assim como extensão lateral inferior a $3 / 4$ da circunferência; limite de quatro lesões. As técnicas de ressecção são a mucosectomia ou dissecção endoscópica de submucosa- DES, além de ablação por terapia fotodinâmica, plasma de argônio, YAG-laser ou radiofrequência. As modalidades ablativas não permitem análise histopatológica da lesão neoplásica erradicada, necessária para avaliação da suficiência da intervenção endoscópica. Logo, os métodos ablativos não são indicados para o tratamento endoscópico do carcinoma de células escamosas do esôfago. (ARANTES, 2012).

A esofagectomia transhiatal é realizada por meio das vias de acesso abdominal e cervical. O tempo abdominal é realizado por laparotomia, no qual o estômago é preparado e tubulizado, faz-se a transecção mediana do diafragma e o esôfago médiodistal é dissecado. Procede-se o tempo cervical por meio de incisão paralela à borda anterior do músculo esternocleidomastoideo. Faz-se a esternotomia em sentido longitudinal, desde a fúrcula até ultrapassar o manúbrio e, por conseguinte, a secção óssea toma sentido transversal para a direita, culminando em esternotomia com forma da letra L invertido. (HENRIQUES et al., 2012). Técnicas minimamente invasivas têm sido utilizadas nos estágios iniciais do carcinoma esofágico para melhorar os resultados pósoperatórios em casos de alta morbidade e mortalidade. (PETROPOULOS et al., 2015).

A radioterapia tem como maior meta $\mathrm{o}$ controle locorregional da doença, na tentativa de preservar os órgãos durante a ressecção, a laringe no câncer do esôfago cervical ou o estômago no câncer do esôfago distal. (TERCIOTI JUNIOR, 2011). Na radioterapia radical exclusiva são utilizadas doses elevadas de 60-70 Gy, fracionadas em sessões de 1,8-2 Gy; na radioterapia radical associada à quimioterapia concomitante, as doses de radioterapia são menores, entre 54-60 Gy, utilizando-se Cisplatina, 5- Fluorouracil e o Paclitaxel; na radioterapia neoadjuvante com ou sem quimioterapia concomitante, as doses oscilam entre 39,6-43,2 Gy, em frações de 1,8 Gy, podendo-se elevar essa dose em caso da não realização de quimioterapia simultânea. (MERINO, 2010).

Em relação à quimioterapia, Merino (2010) defende a combinação de vários fármacos, entre os quais, a Cisplatina e o 5Fluorouracil; os Taxanos também têm futuro promissor. (MERINO, 2010).

O tratamento químico da disfagia maligna ocorre a partir da administração de etanol ou polidocanol intratumoral, produzindo necrose tumoral. As experiências clínicas que avaliam esse procedimento são limitadas, sendo necessário retratamento em 
intervalos de 4 a 5 semanas. (MATA, LLACH e BORDAS, 2007).

Outra possibilidade de tratamento é a terapia com alvo molecular específico, na qual o receptor transmembrana de fator de crescimento, do tipo tirosina-quinase, codificado pelo oncogene HER-2, é o alvo. Encontrou-se sua superexpressão entre $30 \%$ e $90 \%$ dos tumores esofágicos, associando-se ao aumento da invasão tumoral e pior prognóstico. Utiliza-se o anti-HER com anticorpos monoclonais (cetuximabe e panitumumabe) ou inibidores de receptor de tirosina-quinase (gefitinibe e erlotinibe). O anticorpo anti-HER-2 (trastuzumabe), combinado à quimioterapia (cisplatina / 5furacil), pode ser alternativa para pacientes com neoplasias da trato esofágico-gástrico (TEG), possibilitando aos doentes com surperexpressão de HER-2, maior sobrevida. (LACERDA, 2013).

Finalmente, Mata, Llach e Bordas (2007) apontam como escolha mais realista o tratamento paliativo para melhora da disfagia contra casos de câncer avançado, sem possibilidade de cura ou diante de comorbidades muito forte, destacando para tanto, a radioterapia externa e endoluminal (braquiterapia), a quimiorradioterapia, a dilatação esofágica, a colocação de stent, a cirurgia endoluminal, além do tratamento com laser e terapia fotodinâmica. Com o objetivo de alimentação e descompressão estomacal, a gastrostomia endoscópica (PEG) também é recomendada.

No caso de fracasso da terapia paliativa ou de pacientes em que tal técnica não for factível, a manutenção de suporte nutricional por sonda nasoentérica é a saída para adequada ingesta calórica. (MATA, LLACH e BORDAS, 2007).

\section{CONSIDERAÇÕES FINAIS}

Dos tópicos apresentados, o que reuniu maior número de referências foi o Tratamento, destacado de forma distinta ou complementar por 14 dos 23 artigos. Em contrapartida, o de menor número foi Histórico, descrito, de maneira limitada, por apenas 1 referência. Entre os periódicos, o mais utilizado foi a Revista Colégio Brasileiro de Cirurgiões, do Rio de Janeiro, com 6 referências, não tendo sido encontrado mais de um artigo em outra revista de mesmo título.

Como síntese, pode-se afirmar que o câncer no esôfago reúne, sob o mesmo nome, 20 diferentes possibilidades histológicas, todas associadas ao desenvolvimento de lesões tumorais, mais ou menos agressivas, mas marcadas pela disfagia, odinofagia e perda de peso, sobre as quais foram registradas, contudo, poucas referências históricas.

Nos artigos analisados foram encontradas três classificações usadas para a a distinção e 
avaliação do estadiamento tumoral, entre as quais, a preconizada pelo (1) Consenso de Paris, que diferencia as lesões segundo seu aspecto protuso, plano ou escavado, e as subclassifica em pediculada, subpediculada e séssil; a (2) Classificação Macroscópica que as divide em vegetante, ulcerada ou infiltrante; e a (3) Classificação de Vienna pTNM, de maior complexidade e referência, que avalia a profundidade do tumor. Nos pacientes em que o tumor não vai além da submucosa, a sobrevida pode chegar a $70 \%$, comparado à sobrevivência de, apenas, 30\% a $50 \%$ dos pacientes nos quais há invasão da musculares própria e adventícia.

Epidemiologicamente, o câncer de esôfago é uma neoplasia maligna relativamente incomum, mas de prognóstico limitado, que acomete mais homens, negros, acima dos 50 anos de idade, e em piores níveis socioeconômicos. No Brasil, a maior prevalência é observada no Rio Grande do Sul, em função do arriscado consumo de chá quente. $\mathrm{O}$ tabagismo e o alcoolismo são outros fatores predisponentes, assim como doenças como a tilose e a hiperceratose. Alguns estudos sugeriram a associação de 95\% dos adenocarcinomas ao esôfago de Barrett e à doença do refluxo gastroesofágico, sendo o esôfago de Barrett (EB) mais observado em homens adultos jovens, brancos e obesos (IMC >30 $\mathrm{Kg} / \mathrm{m}^{2}$ ). Assinalaram, também, a possibilidade de que antagonistas de receptores $\mathrm{H} 2$ e inibidores da bomba de prótons, ao promoverem a proliferação bacteriana sob neutralização do pH gástrico, poderiam aumentar a incidência de adenocarcinoma. O uso de ácido acetil salicílico (AAS) e drogas anti-inflamatórias não-esteroidais, por seu modo, poderiam proteger do adenocarcinoma ao inibirem as ciclo-oxigenases, prostaglandinas e fatores de crescimento tumoral. Do contrário, não foi relatada associação entre esôfago de Barret e câncer epidermóide.

Quanto ao prognóstico, a sobrevivência após 5 anos é desapontadora, variando conforme o tipo histológico e o estágio do tumor. Em uma classificação crescente de 4 diferentes tipos, a sobrevida é de $10 \%$ a $65 \%$; destacando o carcinoma epidermóide tipo basalóide, como a menor, o sarcoma sinovial e o carcinoma epidermóide escamoso como intermediárias, e o carcinoma de células escamosas como a maior.

O sítio mais frequente é o terço médio, apresentando os terços superior e inferior, entre si, percentual semelhante, mas com tendência de aumento no terço inferior em função da crescente incidência de refluxo gastresofágico crônico e Esôfago de Barret (EB). Outros autores defendem o terço médio com $50 \%$ da frequência, o terço inferior com $30 \%$ a $35 \%$ e o terço superior com, apenas $1 \%$.

A maior parte dos autores confirma o tipo epidermóide ou escamoso como o mais incidente, seguido pelo adenocarcinoma; 
outros invertem a mencionada ordem, apontando o adenocarcinoma como o mais frequente, seguido pelo carcinoma epidermóide ou escamoso; o linfoma primário é o mais raro.

Entre as muitas formas de diagnóstico do câncer no esôfago encontram-se o exame endoscópico com biópsia e citologia esfoliativa, a tomografia computadorizada do tórax, o PET-Scan com 18-fluorodeoxiglicose (Positron Emission Tomography), a ultrassonografia endoscópica (USE), a

\section{REFERÊNCIAS}

1-ALENCAR, MHL; BOLDRINI, D; COSTA, AM; OLIVEIRA, ATT; ATTAB, CS. Sarcoma sinovial primário do esôfago. In: Revista do Colégio Brasileiro de Cirurgiões, Rio de Janeiro, v. 39, n. 5, p. 350446, set.-out., 2012. Disponível em: http://www.scielo.br/pdf/rcbc/v39n5/18.pdf. Acesso em: 28 jun., 2015.

2-ARANTES, V; PIÑEROS, EAF; YOSHIMURA, K; TOYONAGA, T. Avanços na abordagem do carcinoma precoce de esôfago. In: Revista do Colégio Brasileiro de Cirurgiões, v. 39, n. 6, p.534543, 2012. Disponível em: https://www.cbc.org.br/wpcontent/uploads/2013/07/revista-no-62012.pdf. Acesso em: 28 jun., 2015.

3-AYALA, RN; GRACIANI, AR; LÓPEZ, CE; MORANDO, FR. Cáncer de esófago: revisión. In: Revista de Posgrado de la VIa Cátedra de Medicina. Corrientes, n. 175, nov., 2007, p. 17-21. Disponível em: $<$ http://med.unne.edu.ar/revista/revista175/5_ 175.pdf>. Acesso em: 31 jun. 2015. toracoscopia e a laparoscopia, destacando-se a endoscopia digestiva alta com biópsia como o mais indicado inicialmente.

Para finalizar, não se pode deixar de ressaltar a terapêutica contra o câncer no esôfago, a respeito da qual existe ampla variedade de referências, mas cuja conduta mais utilizada é a neoadjuvante, que combina quimio e radioterapia em busca da redução tumoral para melhor e mais eficiente ressecção cirúrgica.

4-BATISTA, AARC; PETROIANU, A; MACHADO, ECM; RIBEIRO, VS. Cânceres triplos de células escamosas do esôfago: relato de caso. In: Revista Médica de Minas Gerais, v. 24, n.4: p.18-59, 2014.

5-BRAVO NETO, GP; SANTOS, EG; LOJA, CAS; VICTER, FC; NEVES, MS; PINTO, MF; CARVALHO, CES. Ressecções gástricas menores com linfadenectomia modificada em câncer gástrico precoce com linfonodo sentinela negativo. In: Revista do Colégio Brasileiro de Cirurgiões, Rio de Janeiro, v. 39, n. 3, p 171-246, mai.-jun., 2012.

6-CAMBRUZZI, E; PRUINELLI, R; MILANI, DM; CRUZ, RP; CUNHA, O; CLIVATTI, N. Tumor esofágico de células granulares associado à carcinoma epidermóide: relato de caso. In: $A B C D$ Arquivos Brasileiros de Cirurgia Digestiva, v. 26, n. 2, p. 156-158, 2013.

7-GARBINO, C.; RODRÍGUEZ, R; GONZÁLEZ, S; GERICK, M. Cáncer de esófago a células pequeñas: comunicación de un caso clínico y revisión de la literatura. In: Revista Salud Militar. 
Montevideo, v. 20, n. 1, 2005, p. 27-33.

Disponível em:

<http://www.revistasaludmilitar.com.uy/Volu menes/Vol\%2020/Articulos\%20PDFs/1\%20$\% 200 N C O L O G I A \% 20-$

$\% 20 \mathrm{C} \% \mathrm{C} 3 \% \mathrm{~A} 1 \mathrm{ncer} \% 20 \mathrm{de} \% 20 \mathrm{es} \% \mathrm{C} 3 \% \mathrm{~B} 3 \mathrm{fa}$ go....pdf >. Acesso em: 31 jun. 2015.

8-GARRIDO, PLR. Epidemiología del cáncer de esófago en hospitales públicos de la comunidad autónoma de Madrid: análisis de supervivência. Tese (Medicina). Universidad Complutense de Madrid, 2011.

Disponível em: < http://eprints.ucm.es/13731/1/T30929.pdf>. Acesso em: 31 jun. 2015.

9-HENRIQUES, AC; COSTA JUNIOR, AS; PIRES, AC; GODINHO, CA; WAISBERG, J. Esofagectomia trans-hiatal com esternotomia parcial. In: Revista do Colégio Brasileiro de Cirurgiões. Rio de Janeiro, v. 39, n. 5, p 350-446, set.-out., 2012.

10-LACERDA, CF; OLIVEIRA, ATT; GUIMARAES, DP; REIS, RM. Câncer de esôfago, da clínica à biologia molecular. In: Revista Onco. Novembro-Dezembro 2013, p. 26-30. Disponível em:

http://revistaonco.com.br/wpcontent/uploads/2013/11/esofago.pdf . Acesso em 31 mai., 2015.

11-MATA, A.; LLACH, J.; BORDAS, J.M.. Cáncer de esófago. Tratamiento paliativo del cáncer de esófago. In: Gastroenterología y Hepatología Continuada. Barcelona, v. 6, n. 2, mar-abril, 2007, p. 68-71. Disponível em: < http://www.ghcontinuada.com/ contenidos /pdf/v6n2a398pdf001.pdf>. Acesso em: 31 jun. 2015.

\section{2-MERINO, GA. Braquiterapia} endoluminal en el tratamiento del cáncer de esófago. Santiago de Compostela, 2010. Disponível em:

<http://www.sergas.es/docs/Avalia-t/CT201004-braquit-esofago.pdf $>$. Acesso em: 31 jun. 2015.
13-PLAZAS, JG. Cáncer de esôfago. In: Revista de la Sociedad Espanôla de Oncología Médica, 2015. Disponível em: $<$ http://www.seom.org/en/informacion-sobreel-cancer/info-tiposcancer/digestivo/esofago?format $=\mathrm{pdf}>$. Acesso em: 31 jun. 2015.

14-QUEIROGA, RC; PERNAMBUCO, AP. Câncer de esôfago: epidemiologia, diagnóstico e tratamento. In: Revista Brasileira de Cancerologia, v. 52, n. 2, p. 173-178, 2006. Disponível em: http://www.inca.gov.br/rbc/n_52/v02/pdf/revi sao3.pdf. Acesso em 28 mai., 2015.

\section{5-SEINELDIN S, SEINELDIN, C. Cáncer} de esófago. In: Enciclopedia de Cirugía Digestiva, 2007; t. I-184, p. 1-19. Disponível em: <http://www.sacd.

org.ar/uochentaycuatro.pdf $>$. Acesso em: 31 jun. 2015.

16-SEQUEIRA, TZ; BRENES, AC. Revisión bibliográfica de cáncer de esófago. In:

Revista Médica de Costa Rica y

Centroamerica. San José. v. 69, n. 604, 2012, p. 539-544. Disponível em:

<http://www.binasss.sa.cr/revistas/ rmcc/604/art18.pdf>. Acesso em: 31 jun. 2015 .

17-SOLARI, CZ. Enfermedades del esófago. In: Tópicos Selectos em Medicina Interna Gastroenterología. 2010, p. 138-153.

Disponível em: <

http://www.cmp.org.pe/documentos/librosLib res/tsmi/Cap9_Enfermedades_del_esofago.pd $\mathrm{f}>$. Acesso em: 31 jun. 2015.

18-TERCIOTI JUNIOR, V; LOPES, LR; COELHO NETO, JS; CARVALHEIRA, JBC; ANDREOLLO, NA. Eficácia local e complicações da terapêutica neoadjuvante no carcinoma epidermóide do esôfago: radioterapia versus radioterapia associada à quimioterapia. In: Revista do Colégio Brasileiro de Cirurgiões, v. 38, n. 4, 2011. 
19-TORTOSA, LG. Esófago. In:

CARRIELLO, AH.; DEFLITTO, JR. In:

Cirugía: bases clínicas y terapéuticas. $1 \mathrm{ed}$.

La Plata. 25 out. 2012. p. 793-810.

20-VEAS, R C; FLISFISCH, FH. Cáncer

esofágico. In: Revista Medicina y

Humanidades. Santiago. v. 3, n 1-2, p. 34-38,

2011. Disponível em: <http://www.

medicinayhumanidades.cl/ediciones/n1_2201

1/05_CANCER_ESOFAGO.pdf >. Acesso em: 31 jun. 2015.

21-WÜNSCH FILHO, V; MIRRA, AP; LÓPEZ, RVM; ANTUNES. Tabagismo e câncer no Brasil: evidências e perspectivas.
In: Revista Brasileira de Epidemiologia. São Paulo, v. 13, n. 2, p. 175-187, 2010.

22-XIMENES NETTO, M; FERNANDES FILHO, R; BRITO, F. Câncer de Esôfago. In: SBCT. (Org.). In: Tópicos de Atualização em Cirurgia Torácica. 1ed.: FMO, 2011, v. 1, p. 474-487. Disponível em:

http://www.sbct.org.br/pdf/livro_virtual/cance r_de_esofago.pdf. Acesso em: 02 jun., 2015.

23-XIMENES NETTO, M; PIAUILINO, MA; OLIVEIRA, HA; VAZ NETO, JP.

Linfoma esofágico primário. In: Revista do Colégio Brasileiro de Cirurgiões, v. 39, n. 3, p. 243-246, 2012. 